
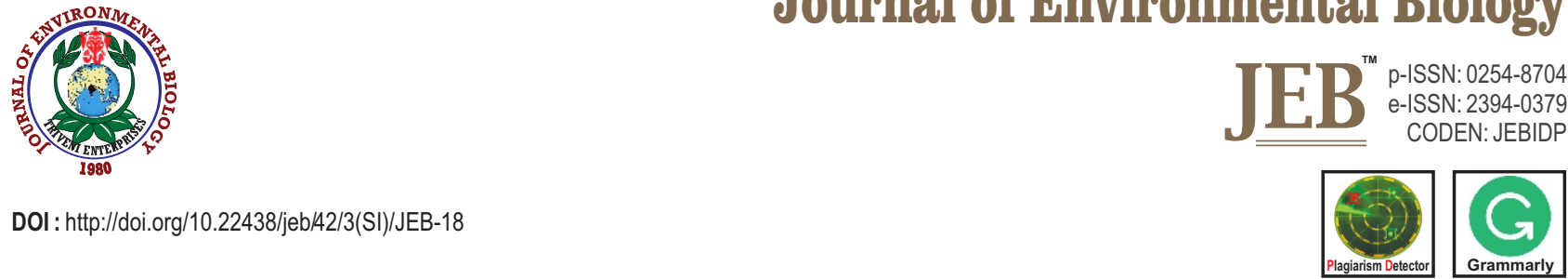

\title{
Contribution of root tensile of Pennisetum polystachion on shear strength of sandy soil in slope bio-engineering technique
}

\author{
Z.A. Rahman*, A.E. Ettbeb, W.M.R. Idris and S.N.A. Tarmidzi \\ Department of Earth Science and Environment, Faculty of Science and Technology, Universiti Kebangsaan Malaysia, Bangi, 43600, Malaysia \\ *Corresponding Author Email : zarah1970@ukm.edu.my
}

\section{Abstract}

Aims: In soil bio-engineering, plant has been widely adopted as important material in promoting sustainable ecological function in slope instability measures. Plant canopy provides shelter and at subsurface level, root networking attributes toward stability of soil against erosion and slope failure. To investigate the potential of selected P. polystachion as biological material in soil bio-engineering for improving the soil shear strength of sandy soil planted with P. polystachion.

Methodology: The selected species was initially planted using hyroseeding technique on studied plots which facilated with and without fiber netting (made of paddy straw). A control plot was also prepared for reference of this study. The plots were routinely watered twice a day for six months before experimental program was scheduled for determining of root tensile and soil shear strength tests.

Results: The root tensile strength of $P$. polystachion exhibited a positive significant relationship between root tensile force and root diameter. The shear strength of soil was affected by the presence of root if compared to that of soil without root (control). Biomass analysist also agree with the soil water content, $w_{s}$. High biomass contributed to the increase in the values of soil shear strength parameter of cohesive, $c$ and angle of friction, $\theta$ for root-permeated soil with P. polystachion.

Interpretation: This study has suggested that the potential application of this selected species for slope vegetation in improving the erosion control and slope stability in soil-bioengineering scheme.

Keywords: Erosion, Pennisetum, Root tensile, Shear strength

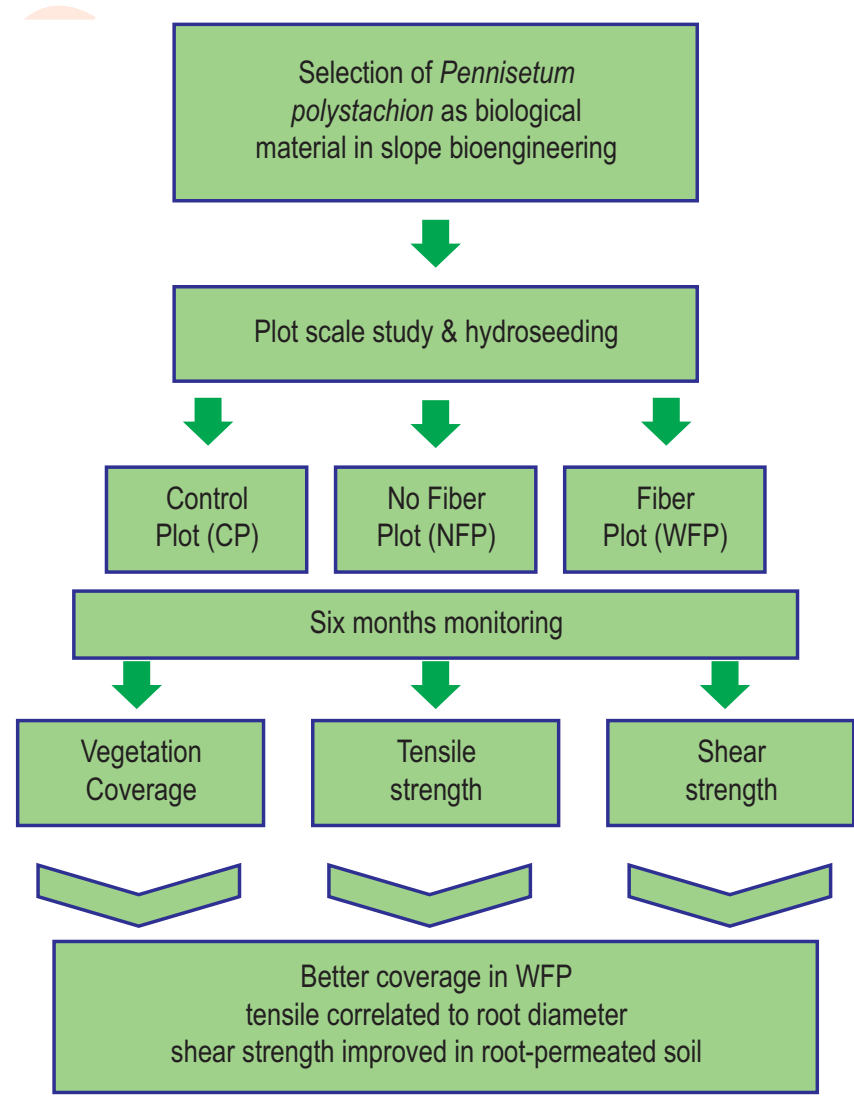

How to cite : Rahman, Z.A.,A.E. Ettbeb, W.M.R. Idris and S.N. Ahmad Tarmidzi: Contribution of root tensile of Pennisetum polystachion on shear strength of sandy soil in slope bio-engineering technique. J. Environ. Biol., 42, 857-864 (2021). 


\section{Introduction}

Erosion and slope instability are common features in tropical regions which experience heavy downpour during wet season. Malaysia is located near the equator and remains hot and humid throughout the year with temperature ranging from $23^{\circ} \mathrm{C}$ to $33^{\circ} \mathrm{C}$. Rainy season is generally caused by North east monsoon from October and March that bring heavy rainfall mainly to the east coast states of Peninsular Malaysia. In highland areas, the temperature gets mild with temperature ranging between $17^{\circ} \mathrm{C}$ and $25^{\circ} \mathrm{C}$. During wet season, several erosion and slope failures are observed annually that cause loss of properties and life.

Soil is prone to erosion especially barely open to erosion agents such wind and water. Soil erosion can occur even on flat and gentle slopes but at slow rate, however, can be extremely worst when the slope is openly barren, steep and having heavy rainfall (Osman et al., 2011). Gray and Sotir (1996) cited that the removal of slope vegetation is among the controlling factors that also contributes to slope instability. With prolong weathering, the soil strength is slowly degrades with time and begins to associate with small scale surface erosion. It almost the climatic elements become a triggering factor to the problem of soil erosion (Gray and Ohashi, 1983). Number of steps have been taken and million have been spent to tackle down this problem by imposing schemes that can improve the stability of slope, especially those associated with engineered soil slopes. Hard engineering such as retaining wall, shorcrete, nailing and netting etc., are among common options used in slope mitigation measures. The use of soil-bioengineering approach has been successfully utilized in combination with hard engineering. This technique manages to control soil erosion at embankment sites, river banks and exmined areas (Muzzi et al., 1997; Oliveira et al., 2012). Use of plants for slope erosion management can benefit soil environments which involves modification of soil biophysical, chemical and mechanical properties that finally stimulate the diversity and abundance of micro-organisma (Stokes et al., 2014). Mutual interaction between soil and root has been well acknowledged by researches. Ali and Osman (2008) and Mattia et al. (2007) stated that the role of vegetation on soil reinforcement is associated with factors related to soil types, plant species and coverage and soil moisture condition. Roots penetrate down into the ground and bind together soil particles and refrain soil movement through their tensile resistance, subsequently improving the shear strength of soil. Previous studies have reported that vegetated slopes are less vulnerable to erosion caused by water and wind actions (Coppin and Richards, 1990; Gray and Sotir, 1996; Preti and Giadrossich, 2009).

Many plant species like Vetiver (Vetiveria zizanioides), Signal (Brachiaradecumbens) and Bermuda (Cynodon dactylon) grasses have been used for slope application. These plants have been successfully able to control soil erosion and at sub-surface level improve the structure of soil through their root characteristics. Vertiver grass is characterized by densely tufted bunch and can easily established in many part of the world (Oshunsanya et al., 2014). There are many native species that can also be adopted and should be examined their potential application as biological material. Pennisetum polystachion is a type grass species well established in many countries in tropical region (Bhattacharjee et al., 2007). Native plants are widely distributed and can offer cheaper maintenance and can definitely tolerate local environments (Lasamadi et al., 2013; Tosi, 2007). In addition, use of local species can be an added-value, ecomomically cost-effective and can diversify with the current products available in the market. In view of the above, this study aimed to investigate the tensile resistance, in terms of force for the selected Pennisetum species and to determine the effect of root-permeated soil on the shear strength of soil planted with $P$. polystachion. This species was initially planted in studied plots pre-installed with and wihout fiber net. Fiber net is also known paddy straw blanket which provided by supplier. A control plot was also prepared for reference and comparison.

\section{Materials and Methods}

Pennisetum polystachion (Linnaeus) Schultes was selected for this study. This parrenial plant is commonly known as mission or foxtail grass. It can grow up to $2 \mathrm{~m}$ and has been introduced purposely as a fodder grass. It is believed that this species spread from Thailand into Malaysia in early 1980 (Bakar et al., 1990). This plant is a dominant weed in deforested lands, harmful to agricultural plants and treated as un-economically useful.

The selected plot study by the soil which developed from the weathering of granitic rock. The soil was yellowish red with abundant coarse quartz grains in the soil mass. The physicochemical characteristics of soil is shown in Table 1.

Preparation of plots and hydroseeding: P. polystachion was initially planted in the plots following the hydroseeding technique. Prior to that, mature seeds were collected from various road sites from Gap to Fraser Hill. The studied plots were prepared at Fraser Hill's Research Center (PPBF UKM) with average slope angle of $40^{\circ}$. Bukit Fraser is a mountaineous area with elevation between 1000 to $1525 \mathrm{~m}$ above sea level with temperature ranging $18^{\circ} \mathrm{C}$ to $22^{\circ} \mathrm{C}$ (Sahibin et al., 2015). The average annual rainfall is 2624 $\mathrm{mm}$ and relative humidity $65 \%$ and $90 \%$. The studied plots consisted of different type of plots namely control plot (CP), plot with fiber netting or paddy straw blanket (WFP) and plot without fiber netting (NFP). The dimension of each plot was $500 \mathrm{~cm} x$ $200 \mathrm{~cm} \times 30 \mathrm{~cm}$ and was built with sand brick.

Hydroseeding mixture consisted of soil tacifier, seed, water, fertilizer and paper mulch made up hydroseeding mixture. The amount of each component was prepared based on the 
Table 1: Physico-chemical characteristics of soil

\begin{tabular}{ll}
\hline Parameters & Soil \\
\hline pH H20 $(1: 1 ;$ w/v) & $5.67 \pm 0.58$ \\
Spesific gravity, $G_{s}$ & $2.63 \pm 0.15$ \\
Organic cont. $(\%)$ & $5.50 \pm 1.27$ \\
Water cont. $(\%)$ & $31.79 \pm 9.52$ \\
Sand $(\%)$ & $69.35 \pm 2.13$ \\
Silt $(\%)$ & $19.28 \pm 3.05$ \\
Clay $(\%)$ & $11.37 \pm 1.26$ \\
Texture & Sandy loam \\
\hline Hydraulic conduct., $K(\mathrm{sm} / \mathrm{j})$ & $0.15-0.63$
\end{tabular}

standard procedure provided by the supplier, Hydroturf Services (M) Sdn. Bhd. Recycled papers for paper mulch material were soaked in water for several days and the water was change everyday till the $\mathrm{pH}$ of water was neutral. The soaked papers then were blended before oven-dried at $70^{\circ} \mathrm{C}$ for a week. The predetermined paper mulch and seed were mixed with distilled water and left for $36 \mathrm{hr}$. The soil tacifier and organic fertilizer were added. The mixture was then thoroughly blended again until it had a slurry texture. The amount of each component in hyroseeding mixture is shown in Table 2. Hyroseeding slurry was manually and uniformly sprayed on each plot. Each type of plot was duplicated to allow statistical analysis. The plots were monitored for six months and watered twice a day.

Vegetation coverage: The studied plots were monitored every month up to six months period. To assess the performance and influence of fiber net which was installed prior to hydroseeding to P. polystachion during this period of observation. Fiber net or paddy straw blanket was also supplied by Hydroturf Service Sdn Bhd (M). Paddy straws were layered and woven by polypropylene of mesh size $13 \mathrm{~mm} \times 13 \mathrm{~mm}$. This product can absorb and dissipate energy from raindrops which will benefit the hydroseeding material and top soils from being washed away to the toe of the slope. It also offers surface roughness to decrease the velocity of runoff, subsequently reduce the sediment transportation (Won et al., 2012). Each plot was divided into 10 grids of $1 \mathrm{~m}^{2}$ each. Every month, the vegetation coverage area was determined by measuring the boundary of successful growth of $P$. polystachion over total area of the plot.

Root tensile strength test: Root sampling was carried for tensile resistance test. This was carried out after six months for physical characterization. Selected plants from each plot were carefully dug and washed with tap water to remove dirt attached to the roots. Roots were for root diameter using a venier caliper. This measurement was carried out at three different points of the root. Root samples were cut into $10 \mathrm{~cm}$ length and then weighed using balance (Model Mettle PJ3000, made in Japan). Each end of the root sample was wrapped with sand paper (ASTM D3379-75 1989). The root was then clamped into the entire wedge grip
Table 2: Proportion amount of each component in hydroseeding

\begin{tabular}{ll}
\hline Component & Quantity \\
\hline Seed $\left(\mathrm{g} \mathrm{m}^{-2}\right)$ & 27 \\
Paper mulch $\left(\mathrm{g} \mathrm{m}^{-2}\right)$ & 125 \\
Soil tacifier $\left(\mathrm{ml}^{-2}\right.$ & 3 \\
Fertilizer $\left(\mathrm{g} \mathrm{m}^{-2}\right)$ & 31.25 \\
Distilled water $(\mathrm{ml})$ & 300 \\
$\mathrm{pH}$ & 5.48 \\
\hline
\end{tabular}

length to ensure better grip with little risk of slippage during the test. The rate of $5 \mathrm{~mm} \mathrm{~min}^{-1}$ was applied to pull vertically up of the root sample. The root was carefully monitored until failure occurred and the reading of maximum force was recorded automatically by software embedded with Universal Testing Machine (UTM). This device can apply extension force up to $50 \mathrm{kN}$ (Instron, Model 5566, USA). The tensile force at the point of rupture was taken as peak load (Fmax) (Abdi et al., 2010; Genet et al., 2011; Vergani et al., 2012). The diameter of root was measured again after the test at several points close to the point of ruptures and average value was recorded.

The relationship between tensile force and root diameter is shown in Eq.1.

$$
T_{f}=\alpha \cdot d^{\beta}
$$

Where, $T_{f}$ is the tensile force $(\mathrm{N}), d$ is the average root diameter (mm). (Genet et al., 2011; Schmidt et al., 2001; Tosi, 2007). Tensile stress was determined by dividing the tensile force over the cross-sectional area of the root at rupture point (Abdi et al., 2010). Arguments arose as a result of the difficulty in achieving accurate measurement at the point of rupture and uncertainty in the exact point of rupture especially for finer roots. In addition, the diameter of root usually reduce after the test caused by tensile strain and the rupture, process is associated with a small proportion root rather than a single infinitesimal section (Vergani et al., 2012).

Soil sampling and direct shearbox test: The collection of soil samples for direct shearbox test was carried out from different types of plots (CP, NFP and WFP). A box sample technique was adopted and random sampling was applied for each plot. A metal knive was used to dig out a box sample and each box sample had approximate dimension of $200 \mathrm{~mm} \times 200 \mathrm{~mm} \times 100 \mathrm{~mm}$. The sample was carefully dug out from the ground and was wrapped with several layers of plastic film to maintain its moisture content prior to laboratory test. In laboratory, the box sample was unwrapped and was the trimmed to fit into brass box of direct shearbox equipment ( $60 \mathrm{~mm} \times 60 \mathrm{~mm} \times 25 \mathrm{~mm}$ ). Then brass box with sample was attached back to the shearbox machine and the sample was horizontally sheared at a strain rate of $1.2 \mathrm{~mm} \mathrm{~min}^{-1}$. Three samples were prepared for each type of plot. Each sample from the plot types would be sheared under apllied normal loads, 
$\sigma_{n}$ of 10,20 and $30 \mathrm{kPa}$. The procedure of perfoming shearbox test for soil was accordance to the British Standard Institution 1377 (1990).

The equation of Mohr-Coilomb's soil shear strength was applied to establish the shear strength parameters of angle of friction and cohesion values (Eq.2) .

$$
\tau=C s+\sigma \cdot \tan \theta
$$

Where, $\mathrm{C}_{\mathrm{s}}$ is the soil cohesion; $\theta$ the angle of friction, $\sigma$ the normal load and $\tau$ is the soil shear strength. In the case of the presence of root in soil matrix, this equation should take into account the role of root in providing resistance toward failure which contribute to additional shear strength to the soil by $C_{r}$ as shown in Eq.3 (Bischetti et al., 2009; Cislaghi et al., 2017; Roering et al., 2003; Wu, 2017).

$$
\tau=\mathrm{Cs}+\mathrm{Cr}+\sigma \cdot \tan \theta
$$

After the completion of shearing, the moisture content and root biomass were determined for each sample. The sheared sample was weighed and transferred into the oven at $105^{\circ} \mathrm{C}$ for an overnight. The sample was weighed again to measure the moisture content. The sample was gently washed to remove soil and the roots were oven dried in an oven at $60^{\circ} \mathrm{C}$.

\section{Results and Discussion}

Vegetation cover was measured every month up to six months. The results of this observation is shown in Fig. 1. The control plot was empty as this plot was left barren without hydroseeding. Early coverage up to 30 days was slow but plot with fiber net (WFP) reached $47.5 \%$ whilst plot without fiber net (NFP) only achieved $32.5 \%$. The following months (60 days), vegetation coverage for WFP and NFP reached $75 \%$ and $57.5 \%$, respectively. It took 90 days for WFP to establish $100 \%$ vegetation coverage, while NFP managed $95 \%$ up to the end of observation period. Difference in vegetation coverage between these two plots may be attributed to removal of some seeds by water run-off from the plot without fiber net (NFP). The presence of fiber net can shelter or trap seeds and create optimum condition for the seedling process. Based on this study, the use of fiber net to plot can produce successful growth of studied species at quicker phase when compared with plot having no fiber net.

A series of tensile resistant tests were performed on root samples which were collected after six months. Forty-eight root samples were uprooted carefully and cleaned before the samples were prepared for the test. The root diameters ranged between 0.19 and $0.49 \mathrm{~mm}$ with average of $0.36 \mathrm{~mm}$. The tensile force values ranged between $2.10 \mathrm{~N}$ and $9.98 \mathrm{~N}$ with average of 5.35 (Table 3).

The relationship between root tensile force and root diameter is shown in Fig. 1. This relationship can be best represented by a power low equation to encompass the scattered values of tensile force and diameter (Eq.4) .

$$
T_{f}=22.79 d^{1.448} R^{2}=08018
$$

The relationship between tensile stress and root diameter resulted in inverse power law equation. However, there were some doubts in accuracy, a preferable approach was to used tensile force instead of stress. Small variation can be clearly seen in Fig. 2, however this relationship in power law equation is supported by good correlation $\left(R^{2}=0.8018\right)$. This study indicates that higher root tensile force reflects its tensile strength towards better resistance to tension force when slope experiences soil movement (Stokes et al., 2009). The potential failure plane will be refrained from movement when the root networking binds the soil particles and failure plane together (Ghestem et al., 2014). At this state, the slope still stable and tension force driven by slope was below the maximum root tensile strength. The stability of particular slope can be extensively improved as roots infiltrate deep and anchors to slope materials. In addition, factor such as density, network and types of root can vary and contribute to the stability of slope (Dupuy et al., 2005; Mickovski et al., 2007).

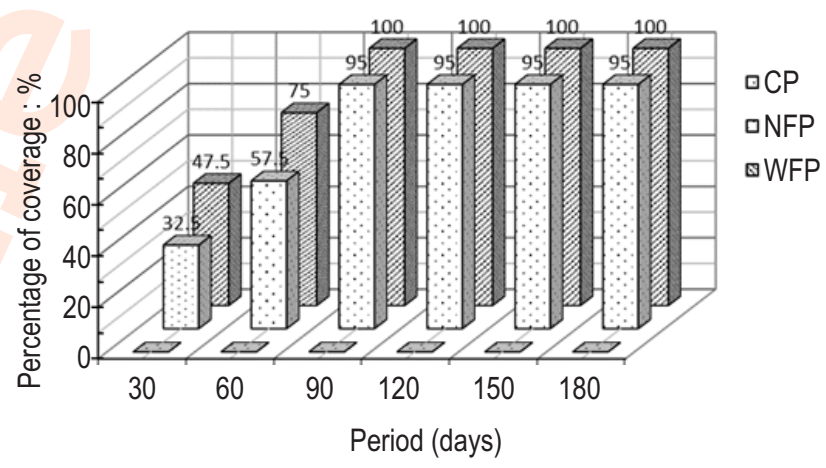

Fig. 1: Trend of vegetation coverage of studied species over six months period

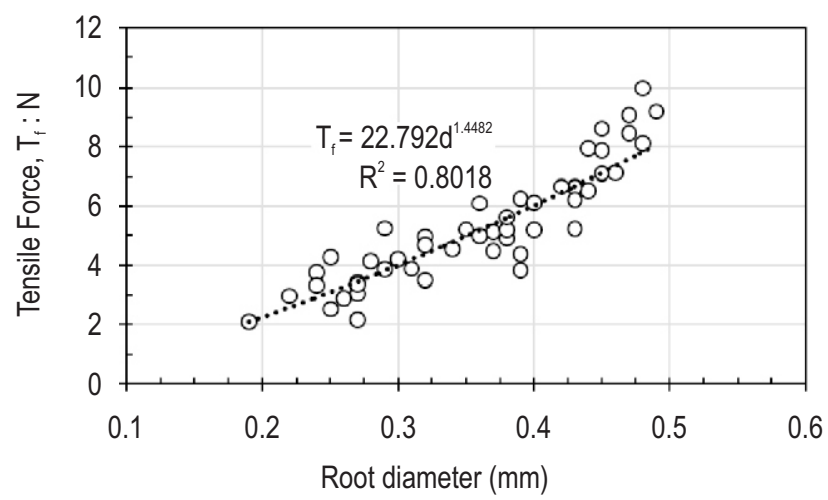

Fig. 2 : A positive relationship of tensile force against root diameter. 
A series of direct shearbox test were performed to the samples of root-permeated soil. Stress against displacement curves for different plot treatment can be seen in Fig. 3a, b, c. All stress-displacement curves showed a typical behavior where stresses initially climbed linearly up to early displacement approximately below $0.5 \mathrm{~mm}$. The rate of stress over displacement gradually decreased before achieving the resistance peaks, followed by constant values. Three different normal loads were applied to achieve peak values for each type of sample. The resistance peaks increased as the applied normal stress increased. Samples from NFP showed peak resistances close to the end of the tests, suggesting a characteristic of strained hardening behavior or non-compacted soil (Ali Rahman et al., 2010; Maffra et al., 2019).

The shear strength parameter, biomass and water contents for different plot treatments are shown in Table 4. For control plot (CP) with applied normal load of $10 \mathrm{kPa}$, the shear

Table 3: Root diameter and tensile force values for studied species

\begin{tabular}{lllllll}
\hline & \multicolumn{2}{l}{ Root diameter $(\mathrm{mm})$} & & & \multicolumn{2}{c}{ Tensile force $(\mathrm{N})$} \\
\cline { 1 - 2 } & Maximum & Mean & & Minimim & Maximum & Average \\
\hline 0.19 & 0.49 & $0.36 \pm 0.08$ & 2.10 & 9.98 & $5.35 \pm 1.94$ \\
\hline
\end{tabular}

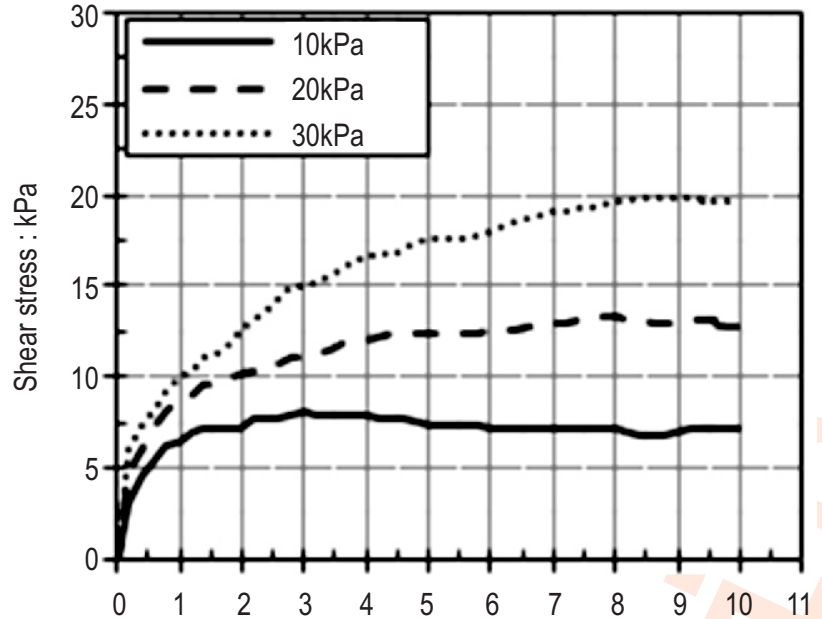

(a)

Displacement: $\mathrm{mm}$
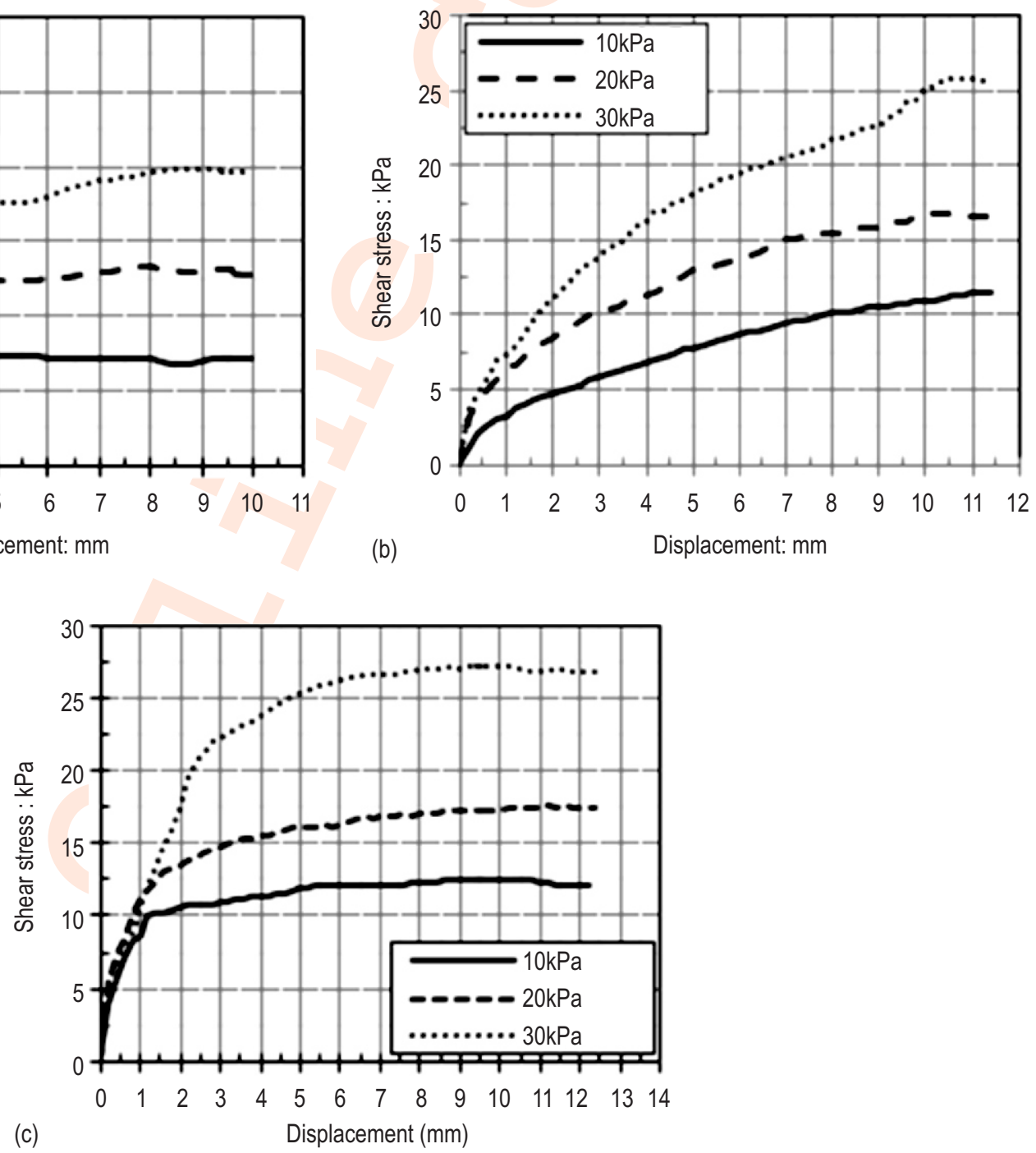

Fig. 3: Stress-displacement curves for different type of treatments (a) control plot (CP); (b) plot with no fiber net (NFP) and (c) plot with fiber net (WFP). 


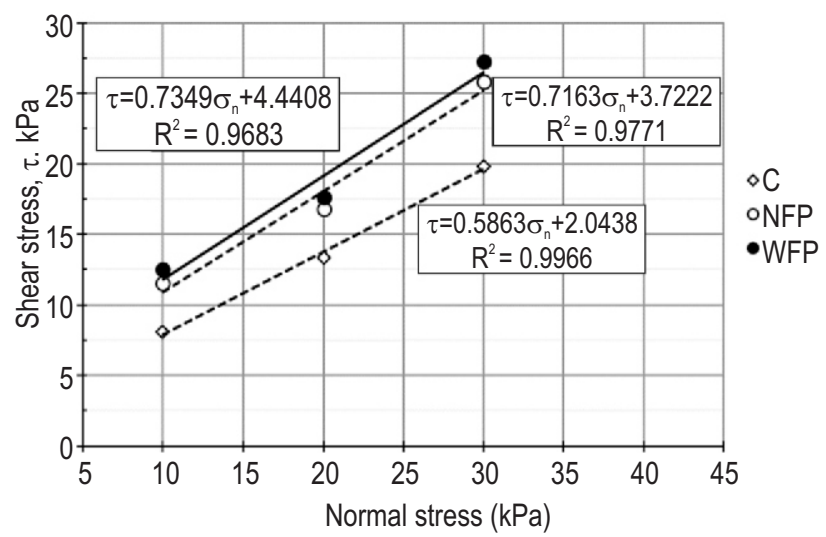

Fig. 4 : Comparison of shear strength envelopes for samples from different plot treatments.

stress achieved its peak resistance at $8.1 \mathrm{kPa}$ (Fig. 3a). While for higher applied stress of $20 \mathrm{kPa}$ and $30 \mathrm{kPa}$, the peak resistance reached higher values of $13.4 \mathrm{kPa}$ and $19.8 \mathrm{kPa}$, respectively. The cohesion and friction angle values for $\mathrm{CP}$ sample, lower than the NFP and WFP samples. The internal friction angle of sample from CP was $30.4^{\circ}$ while for NFP and WFP it was $35.6^{\circ}$ and $36.3^{\circ}$, respectively (Table 4). Apparently, the presence of root exhibited increase in shear strength mainly by increase in the internal friction angle. Since this soil is dominated by sand fraction, the small value of cohesive is expected for sandy soil.

The cohesion value from $\mathrm{CP}$ plot was $2.04 \mathrm{kPa}$ and increased to $3.72 \mathrm{kPa}$ and $4.44 \mathrm{kPa}$ for NFP and WFP samples, respectively. These results showed that the root-permeated soils have higher shear strength parameters if compared to that of sample from control plot (CP) with no root. A study conducted by Maffra et al. (2019) also showed that the shear strength of sandy soil is due to the presence of roots. They found that the shear stress significantly increased between sandy soil without root and root-permeated soil. Studies also showed that the internal friction angle of sandy soil underwent minor rearrangement caused by roots (Ali and Osman, 2008; Veylon et al., 2015). Sandy soil has little cohesion, and resistance effectively comes from friction due to interaction between particles. Roots establish interconnection between two parts of soil which is splitted by potential surface of failure and may fail to rupture once the root tensile strength is overcome (Gray and Sotir, 1996; Maffra et al., 2019). As a result, the soil deformation will delayed at higher strain and achieve resistance peak which causing the increment of cohesion (Maffra et al., 2019).

The failure envelopes for different plots of CP, NFP and WFP are presented in Fig. 4. In comparison between these failure envelopes show that the internal friction angle of the soil (angular coefficient) and cohesion values (cohesive intercept) were located higher in the root-permeated soil samples than soil with no roots. As seen in the figure, the failure envelope for CP soil was distant below the envelopes for NFP and WFP soils. Both failure envelopes for root-permeated soils were located slightly close to each other. Different values for internal friction angle and cohesion values between NFP and WFP plots were $0.7^{\circ}$ and 0.72 $\mathrm{kPa}$, respectively. The contents of root biomass in NFP and WFP samples had contributed slightly to different shear strength parameters (Table 4). Installation of fiber netting to WFP plot provides a better approach to protect the hydroseeding mixture (seed, fertilizer etc) from being washed away by surface runoff during heavy rainfall. The amount of water content has subsequently improved for sample from WFP (43.4\%) compared to that of sample from NFP $(23.7 \%)$. This coupling effect of fiber net and root biomass has attributed to the moisture content of soil. Beside, roots can intercept the failure plane, additional shear strength can be attributed to matric suction as root water uptake causes partial saturation of shallow soil layers which results in increased matric suction (Simon and Collison, 2002; Yildiz et al., 2019). Pallewattha et al. (2019) also concluded that the shear strength of root-permeated sandy is governed by the level of applied suction.

Pennisetum polystachion was studied for its potential use as biological material in bio-engineering technique for soil slope erosion. Wide distributed and easy adaptation of this plant offer

Table 4 : Summary of shear strength parameters, biomass and water content

\begin{tabular}{|c|c|c|c|c|c|c|}
\hline Treatments & $\begin{array}{l}\text { Normal pressure } \\
(\mathrm{kPa})\end{array}$ & $\begin{array}{l}\text { Peak shear } \\
\text { stress }(\mathrm{kPa})\end{array}$ & $\begin{array}{l}\text { Internal friction } \\
\text { angle }\left({ }^{\circ}\right)\end{array}$ & $\begin{array}{l}\text { Cohesion value } \\
(\mathrm{kPa})\end{array}$ & $\begin{array}{l}\text { Average } \\
\text { biomass (g) }\end{array}$ & $\begin{array}{l}\text { Mean water } \\
\text { content (\%) }\end{array}$ \\
\hline Control plot & $\begin{array}{l}10 \\
20 \\
30\end{array}$ & $\begin{array}{l}8.1 \\
13.4 \\
19.8\end{array}$ & 30.4 & 2.04 & n.a & 20.5 \\
\hline Plot without fibre & $\begin{array}{l}10 \\
20 \\
30\end{array}$ & $\begin{array}{l}11.5 \\
16.8 \\
25.8\end{array}$ & 35.6 & 3.72 & 0.59 & 23.7 \\
\hline Plot with fibre & $\begin{array}{l}10 \\
20 \\
30\end{array}$ & $\begin{array}{l}12.6 \\
17.6 \\
27.3\end{array}$ & 36.3 & 4.44 & 1.14 & 43.4 \\
\hline
\end{tabular}

${ }^{*}$ n.a = not available (no plant); CP-control plot; NFP-plot without fiber; WFP-plot with fiber 
economical maintenance and eco-friendly to natural environments. The scope of investigation was concentrated on the root tensile strength and attribution to soil shear strength. The tensile resistance was measured based on tensile force at peak instead of stress due to some ambiguity in accuracy of diameter measurement. It is clearly that the tensile force exhibited positive relationship with root diameter of $P$. polystachion. The result of root tensile displayed a significant positive relationship between tensile force and root diameter $\left(R^{2}=0.8018\right)$. The shear strength of root-permeated soil also improved significantly when compared to soil with no roots. The presence of fiber netting slightly improved the shear strength of the plot with fiber net. The increase in shear strength parameters of plot with fiber net coincided with the amount of root biomass which was higher than the plot with no fiber net. Pennisetum polystachion exhibited full coverage in shorter period than plot with no fiber net facilty. The soil moisture content was also significantly higher than the soil samples from control and no fiber plots. Thus, the results indicate that this species can be adopted for hydroseeding approach and with combination of fiber netting, the slope stability can be improved at economic cost of maintenance.

\section{Acknowledgments}

The authors would like to thank UKM for the financial support through research grant GUP-2016-068. The authors also thank the laboratory assistant staffs of Civil Engineering School of Faculty of Engineering and Architecture and FORCE, UKM for assisting in the mechanical testing of root tensile and direct shearbox tests.

\section{Add-on Information}

Authors' contribution : Z.A. Rahman: Shear strength analysis of the soils; A.E. Ettbeb: Growth performance of the species; W.M.R. Idris: Soil characteristics and hydro-seeding; S.N.A. Tarmidzi: Root tensile of the species.

Research content: The research content is original and has not been published elsewhere

\section{Ethical approval: NotApplicable}

Conflict of interest: The authors declare that there is no conflict of interest.

\section{Data from other sources: NotApplicable}

Consent to publish: All authors agree to publish the paper in Journal of Environmental Biology.

\section{References}

Abdi, E., B. Majnounian, M. Genet and H. Rahimi: Quantifying the effects of root reinforcement of Persian Ironwood (Parrotia persica) on slope stability, a case study: Hillslope of Hyrcanian forests, northern Iran. Ecol. Eng., 36, 1409-1416 (2010).

Ali, F.H. and N. Osman: Shear strength of a soil containing vegetation roots. Soils Found., 48, 587-596 (2008).

Ali Rahman, Z., D.G. Toll, D. Gallipoli and M.R. Taha: Micro-structure and engineering behaviour of weakly bonded soil. Sains Malays., 39, 989-997 (2010).

ASTM D 3379-75: Standard test method for tensile strength and Young's modulus for high modulus single-filament materials (Withdrawn 1998). ASTM International, West Conshohocken, PA, USA(1989).

Bakar, B.B., A. Latief and N.A. Puat: The genus Pennisetum in peninsular Malaysia with particular reference to $P$. setosum, a new record for the weed flora. BIOTROP Special Publication, 38, 71-79(1990).

Bhattacharjee, R., L.S. Khairwal, P.J. Bramel and K.N. Reddy: Establishment of a pearl millet [Pennisetum glaucum (L.) R. Br.] core collection based on geographical distribution and quantitative traits. Euphytica, 155, 135-145(2007).

Bischetti, G.B., E.A. Chiaradia, T. Epis and E. Morlotti: Root cohesion of forest species in the Italian Alps. Plant Soil, 324, 71-89 (2009).

British Standard Institution 1377. Methods of Test for Soil for Civil Engineering Purposes-Part 7: Shear Strength Tests (Total Stress). BS1377, London, England (1990).

Cislaghi, A., E.A. Chiaradia and G.B. Bischetti: Including root reinforcement variability in a probabilistic 3D stability model. Earth Surf. Process. Landf., 42, 1789-1806 (2017).

Coppin, N.J. and I.G. Richards: Use of Vegetation in Civil Engineering. CIRIA Publication, London, UK (1990).

Dupuy, L., T. Fourcaud and A. Stokes: A numerical investigation into factors affecting the anchorage of roots in tension. Eur. J. Soil Sci., 56, 319-327 (2005)

Genet, M., M. Li, T. Luo, T. Fourcaud, A. Clément-Vidal and A. Stokes: Linking carbon supply to root cell-wall chemistry and mechanics at high altitudes in Abies georgei. Ann. Bot., 107, 311-320 (2011).

Genet, M., A. Stokes, T. Fourcaud and J.E. Norris: The influence of plant diversity on slope stability in a moist evergreen deciduous forest. Ecol. Eng., 36, 265-275, (2011).

Ghestem, M., K. Cao, W. Ma, N. Rowe, R. Leclerc, C. Gadenne and A. Stokes: A framework for identifying plant species to be used as 'ecological engineers' for fixing soil on unstable slopes. Plos ONE, 9, e95876 (2014).

Gray, D.H. and H. Ohashi: Mechanics of fiber reinforcing in sand. J. Geotech. Eng., 109, 335-353 (1983).

Gray, D.H. and R. Sotir: Biotechnical and Soil Bioengineering Slope Stabilization. John Wiley \& Sons, New York, USA(1996).

Lasamadi, R.D., S. Malalantang, S. Rustandi and S.D. Anis: Pertumbuhan dan perkembanganrumputgajahdwarf (Pennisetum purpureum cv. Mott) yang diberipupukorganikhasil Fermentasi EM $_{4}$."Zootek" Journal,32, 158-171(2013).

Maffra, C., R. Sousa, F. Sutili and R. Pinheiro: The effect of roots on the shear strength of texturally distinct soils. Floresta e Ambiente, 26, 1-11 (2019).

Mattia, C., G.B. Bischetti and F. Gentile: Biotechnical characteristics of root systems of typical Mediterranean species. Plant Soil, 278, 2332 (2007).

Mickovski, S.B., R. Sonnenberg, M.F. Bransby, M.C.R. Davies, K. Lauder, A. Bengough and P.D. Hallett: Shear reinforcement of soil by vegetation. In: Proceedings of XIV ${ }^{\text {th }}$ European Conference on Soil Mechanics and Geotechnical Engineering, Madrid. Millpress Science Publishers, Rotterdam, Netherlands, pp. 1491-1496 (2007). 
Muzzi, E., F. Roffi, M. Sirotti and U. Bagnares: Revegetation techniques on clay soil slopes in Northern Italy. Land Degrad. Dev., 8, 127-137 (1997).

Oliveira, G., A. Nunes, A. Clemente and O. Correia: Testing germination of species for hydroseeding degraded Mediterranean areas. Restor. Ecol., 20, 623-630 (2012).

Oshunsanya, S.O., Are, K. and J.A. Fagbenro: The use of vetiver grass (Vetiveria nigritana Stapf) strips in checking soil loss and improving yields of maize-cassava-cowpea inter-cropping systems in Southwest Nigeria. J. Appl. Agric.I Res., 1, 237-244 (2014).

Osman, N., M.N. Abdullah and C.H. Abdullah: Pull-out and tensile strength properties of two selected tropical trees. Sains Malays., 40,577-585(2011).

Pallewattha, M., B. Indraratna, A. Heitor and C. Rujikiatkamjorn: Shear strength of a vegetated soil incorporating both root reinforcement and suction. Transp. Geotech., 18, 72-82 (2019).

Preti, F. and F. Giadrossichoot: Root reinforcement and slope bioengineering stabilization by Spanish broom (Spartium junceum L.). Hydrol. Earth Syst. Sci., 13, 1713-1726 (2009).

Sahibin, A.R., W.M.R. Idris, Z. Ali Rahman, T. Lihan and A.S. Mohd Isa: Measurement of potential soil erosion at higher altitude at Fraser's Hill using MUSLE's model. In: Proceedings of Scientific Seminar of Raub-Fraser's Hill Corridor (Eds.: H.M.K. Maideen, S.A. Rahim, T. Lihan, Z.A. Rahman, A.D.H. Mohammed, R. Omar, W.M.R. Idris, S.N.A. Tarmidzi, M.A.A. Juhari and N.R. Shaari). Fraser's Hill Research Center, Faculty of Science \& Technology, National University of Malaysia, Bangi, Malaysia (2015).

Roering, J.J., K.M. Schmidt, J.D. Stock, W.E. Dietrich and D.R. Montgomery: Shallow landsliding, root reinforcement and the spatial distribution of trees inthe Oregon Coast Range. Can. Geotech. J., 40, 237-253 (2003).

Schmidt, K.M., J.J. Roering, J.D. Stock, W.E. Dietrich, D.R. Montgomery and T. Schaub: The variability of root cohesion as an influence on shallow landslide susceptibility in the Oregon Coast Range. Can. Geotech. J., 38, 995-1024 (2001).

Simon, A. and A.J.C. Collison: Quantifying the mechanical and hydrologic effects of riparian vegetation on streambank stability. Earth Surf. Process. Landf., 27, 527-546 (2002).

Stokes, A., C. Atger, A.G. Bengough, T. Fourcaud and R. Sidle: Desirable plant root traits for protecting natural and engineered slopes against landslides. Plant Soil, 324, 1-30 (2009).

Tosi, M.: Root tensile strength relationships and their slope stability implications of three shrub species in the Northern Apennines (Italy). Geomorphology, 18, 268-283 (2007).

Veylon, G., M. Ghestem, A. Stokes and A. Bernard: Quantification of mechanical and hydric components of soil reinforcement by plant roots. Can. Geotech. J., 52, 1-11 (2015).

Won, C.H., Y.H. Choi, M.H. Shin, K.J. Lim and J.D. Choi: Effects of rice straw mats on runoff and sediment discharge in a laboratory rainfall simulation. Geoderma, 189, 164-169 (2012).

Wu, T.H.: Root reinforcement of soil: review of analytical models, test results and applications to design. Can. Geotech. J., 50, 259-274 (2013).

Yildiz, A., F. Graf and S.M. Springman: An investigation of plant-induced suction and its implications for slope stability. Proc. Inst. Civil Eng. Geotech. Eng., 172, 520-529 (2019).

Vergani, C., E.A. Chiaradia and G.B. Bischetti: Variability in the tensile resistance of roots in Alpine forest tree species. Ecol. Eng., 46, 4356 (2012). 